\title{
Dirty Nature: Aesthetics and Ecology in Contemporary Art and Animation Exploring the Anthropocene
}

\author{
Joseph Norman \\ $\mathrm{PhD}$ researcher \\ University of Portsmouth \\ 96a Cotswold Road, BN132LB, UK \\ up836190@myport.ac.uk
}

\section{INTRODUCTION}

The research is in the first year of a practice-led $\mathrm{PhD}$ in animation, on the theme of the human connection with nature in the Anthropocene. This presentation explores creative strategies and processes being deployed in developing the animated work.

\section{CAPITALISM V THE PLANET}

In an anthology on climate change, the psychoanalyst John Keene asserts idea that humanity views the planet as an unlimited 'toiletmother', always available to clean up its mess, and capable of absorbing our toxic products indefinitely. Commentator Naomi Klein extends this approach, explaining that environmental catastrophe could be avoided: but it's in the hands of the elite, leading to conflict between capitalism and the planet.

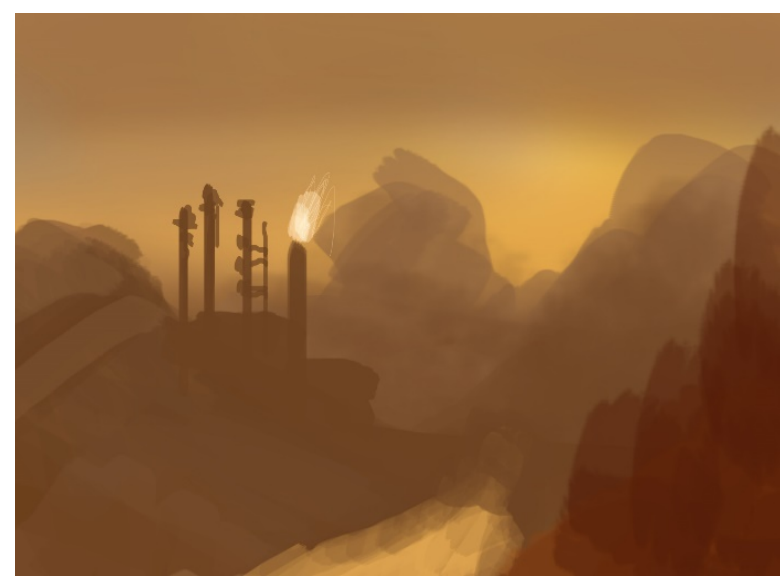

Figure 1: Dirty Landscape 1

In developing a creative strategy, my research involves analysing artists' approaches to the problematization of nature and human society as polarized categories; nature has been historically represented as a pure untainted idyll, for instance in the landscape paintings of the Hudson River School. The dirty Nature that has been constructed through human and industrial activity, especially since the mid-1950s, has necessitated a re-evaluation of the conceptualization of nature and landscape in art.

\subsection{Areas of Focus}

Key approaches I am investigating include:

- The radical eco-poetry of Paula Meehan, in the poem 'Death of a Field'.

- The use of transformative hand-drawn animation processes in the short films of Karolina Glusiec, such as 'Velocity'.

- The wearing of animal and organism masks and costumes in Bjork's 'Biophilia', as a means of transforming identity from human into wild nature, and how this reworks carnival culture.

- The role of the grotesque in treating the human body as a series of openings through which it is connected with nature.

My developing animated work is informed by a Deleuzian model of a rhizomatic connection between shifting elements; this is being investigated through the process of animated transformation from human character to anthropomorphic organism and environment. This overarching web of flux connects diverse elements within the cosmos, ranging from the solar system to the economic landscape. The technical aspects being investigated focus on the use of colour, mark and form as mutating elements, using compositing and animation software, in conjunction with traditional drawing and painting techniques. The work explores the film screen as a 
surface in flux, where transformation of imagery signifies the infiltration of Nature by human activity and pollutants. In Rabelais' story of Pantagruel, the central giant character's body operates as a microcosm, at once containing the whole planet and also fusing with the earth through the cycle of growth and self-renewal. In the middle ages, the earth was conceived as consisting of mountains and precipices, but constructed in the manner of a human body. The research aims to expand on this concept: in the grotesque approach, a body has a kind of double life: in the endless cycle of life, one link joins another (in the chain), where new life is born from old death. The grotesque body is cosmic and universal. It is linked to sun, stars, zodiac, the elements, the cosmic hierarchy. It can merge with landscape, mountains, rivers. The research aims to develop visualization techniques to explore this cyclic narrative, but compromised by industrial dirt. In contrast, Nature's 'dirt', of decay, defecation, sex and eating is being explored as a humorous weapon, with which to maintain the body's cosmic quality and the planet's bodily nature; and thus examine the contemporary connection with Nature.

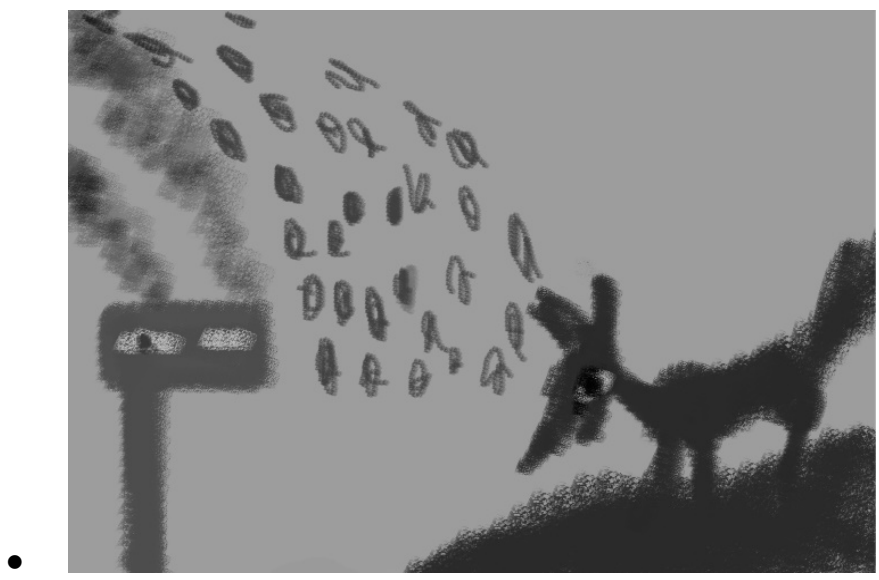

Figure 2: Dirty Landscape 2

\section{REFERENCES}

Bahktin, M. (1984) Rabelais and His World. Edited by $\mathrm{H}$. Iswolsky. $2^{\text {nd }}$ edition. Bloomington: Indiana University Press.

Malm, A. (2015) The Anthropocene myth. Jacobin. https://www.jacobinmag.com/2015/03/anthropocenecapitalism-climate-change/ (accessed 26 February 2017).
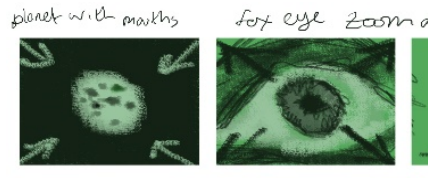

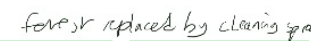

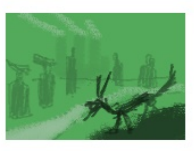

drb river
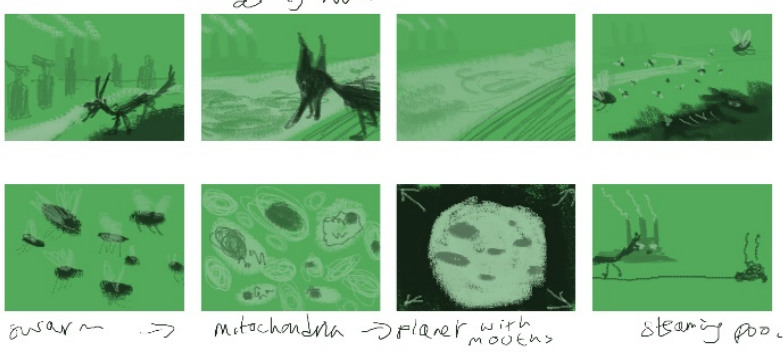

Figure 3: Dirty Nature storyboard 03/2017

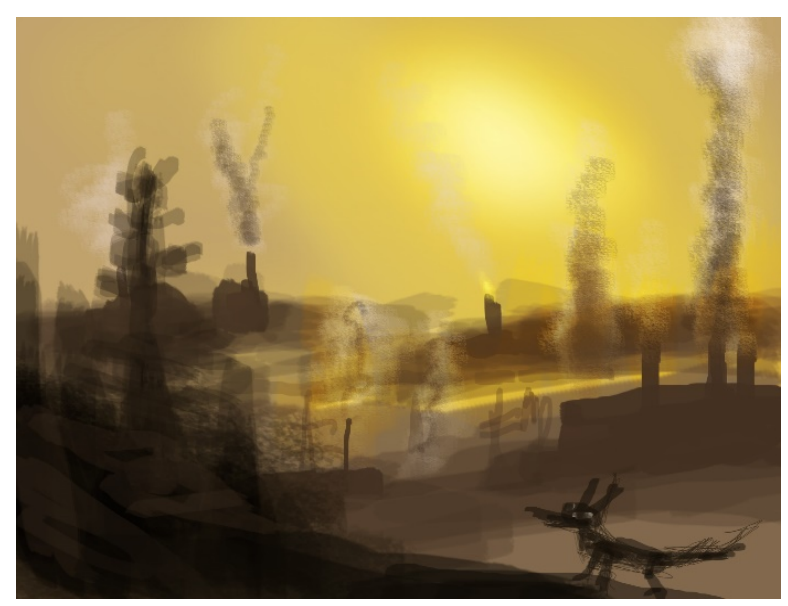

Figure 4: Dirty Nature 3 